\title{
Age Estimation Based on Mandibular Premolar and Molar Development: A Pilot Study
}

\author{
Byung-Yoon Roh ${ }^{1,2}$, Eui-Joo Kim³ ${ }^{3}$ In-Soo Seo ${ }^{1}$, Hyeong-Geon Kim ${ }^{1}$, Hye-Won Ryu ${ }^{1}$, Ju-Heon Lee ${ }^{1}$, \\ Yo-Seob Seo ${ }^{4}$, Ji-Won Ryu' ${ }^{2}$, Jong-Mo Ahn ${ }^{2}$
}

${ }^{1}$ Forensic Medicine Division, National Forensic Service Gwangju Institute, Jangseong, Korea ${ }^{2}$ Department of Oral Medicine, School of Dentistry, Chosun University, Gwangju, Korea ${ }^{3}$ Section of Human Identification, Medical Examiner's Office, National Forensic Service, Wonju, Korea ${ }^{4}$ Department of Oral \& Maxillofacial Radiology, School of Dentistry, Chosun University, Gwangju, Korea

Received November 22, 2021 Revised December 4, 2021 Accepted December 4, 2021

\section{Correspondence to:}

Jong-Mo Ahn

Department of Oral Medicine, School of Dentistry, Chosun University, 309 Pilmundaero, Dong-gu, Gwangju 61452, Korea

Tel: +82-62-220-3896

Fax: +82-62-234-2119

E-mail:jmahn@chosun.ac.kr

https://orcid.org/0000-0002-3615-3688

This study was supported by National Forensic Service, Republic of Korea (NFS2021CLI28).
Purpose: The dental age estimation of children is performed using dental maturity. Postmortem missing of the anterior teeth or the distortion of image of the anterior teeth in panoramic radiographs can make it difficult to analyze the development of the anterior teeth. This pilot study was conducted to derive a new age estimation method based only on the developmental stage of mandibular posterior teeth.

Methods: This study was conducted using panoramic radiographs of 650 subjects aged 3 to 15 years old. The dental developmental stages of the lower left first premolar, second premolar, first molar and second molar were evaluated according to the Demirjian's criteria. The intra-/inter-observer reliability was evaluated, and multiple linear regression analyses were performed including the developmental stage of each tooth as an independent variable.

Results: The intra-/inter-observer reliability was 0.9626 and 0.8877 , respectively, and showed very high reproducibility. Multiple linear regression analyses were performed for males and females, and the age calculation table was derived by obtaining the intercept and the coefficient according to the development stage of each tooth. The coefficient of determination $\left(r^{2}\right)$ of the age calculation method was 0.9634 for male and 0.9570 for female subjects, and the mean difference between chronological age and estimated dental age was -0.42 and -0.21 , respectively.

Conclusions: This pilot study evaluated the developmental stages of four lower posterior teeth in the Korean group according to Demirjian's criteria, and derived age estimation method. The accuracy was lower than when more teeth were used, but it will be useful to estimate age of children when the anterior teeth are difficult to accurately analyze.

Key Words: Age determination by teeth; Panoramic radiography; Tooth development

\section{INTRODUCTION}

Forensic age is estimated based on biological changes that occur throughout life. Age estimation has been used to solve various social and legal problems relating to school entrance, conscription, eligibility for social welfare and pension benefits, criminal law, and for identifying bodies [1]

The increasing number of immigrants and refugees worldwide has increased the need for forensic age estimation [2]. In particular, to solve various social and legal problems related to minors (children and adolescents) whose birth dates cannot be confirmed, age estimation has often

Copyright (C) 2021 Korean Academy of Orofacial Pain and Oral Medicine.

(c) This is an open-access article distributed under the terms of the Creative Commons Attribution Non-Commercial License (http://creativecommons.org/licenses/by-nc/4.0/), which permits unrestricted non-commercial use, distribution, and reproduction in any medium, provided the original work is properly cited. 
been conducted. Such estimation is mainly based on the degree of tooth development, and many studies using this method have been reported [3-5].

Age estimation in South Korea is mainly conducted on adults. In the case of deceased people, age estimation is mainly done for identification purposes, while in the case of living people age assessment is mainly performed to solve problems relating to social welfare, especially pension benefits, as stated above [6-8]. Due to the relatively small number of immigrants and refugees in South Korea, the age of children is rarely estimated; however, it has been used to confirm the identity of missing or dead children [7].

The present study was conducted to derive an age estimation method based only on the development of the posterior teeth. Typically, age estimation methods using teeth require all of them, or all those in one quadrant [9-12]. However, the anterior teeth are often lost postmortem due to their single roots, and can be difficult to analyse accurately on a panoramic radiograph due to image distortion [13]. Considering these challenges, this pilot study aimed to derive an age estimation method based only on the mandibular molars, and then to evaluate its applicability.

\section{MATERIALS AND METHODS}

This retrospective study was based on the panoramic radiographs of patients aged 3 to 15 who visited Chosun University Dental Hospital, South Korea; no radiography was newly conducted for this study. All patient information was anonymously processed and analysed, and only age and sex data were obtained. The mandibular left first and second premolars, and the first and second molars, were analysed; cases in which any teeth had a lesion, such as a severe cavity or cyst, or root canal treatment, an abnormal location or unclear radiographic image, were excluded. In total, 25 males and 25 females were selected for each year within the age range of interest ( $\mathrm{n}=650$ patients) and analysed. The study protocol was approved by the Institutional Review Board of Chosun University Dental Hospital as a research of exemption from the consents of the subjects (approval no.: CUDHIRB 2104002).

We converted panoramic radiographs into JPG files using a workstation (PiViewSTAR PACS; INFINITT Healthcare

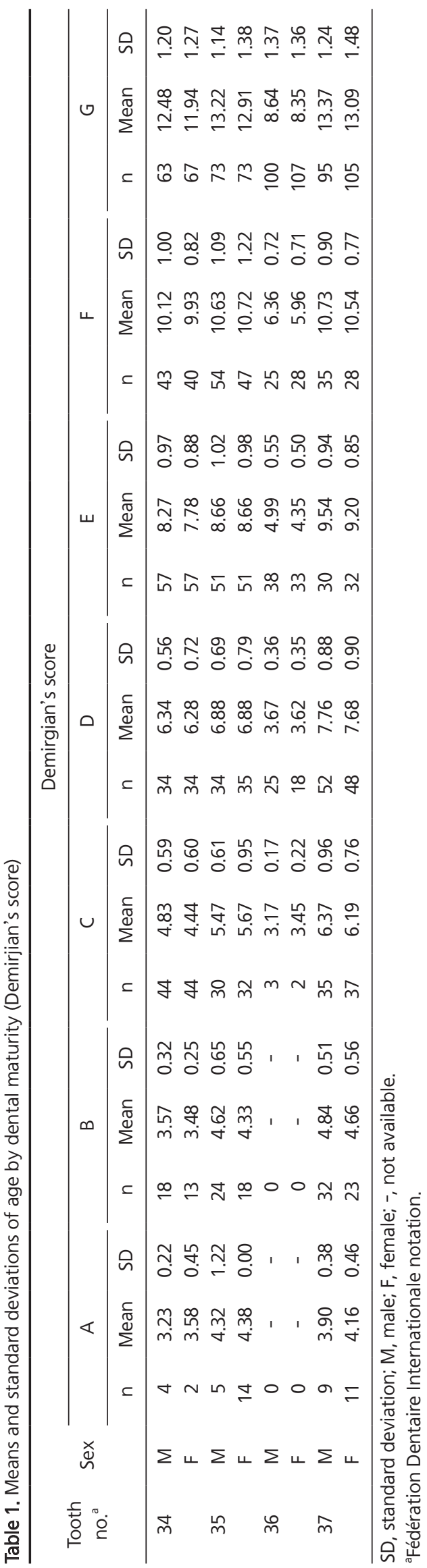


Co. Ltd., Seoul, Korea) and analysed them using Alsee software (ver. 8.26.0.1; ESTSoft Corp., Seoul, Korea). In each radiograph, the dental maturity of the mandibular left first and second premolars, and the first and second molars, was graded (from A to H) using Demirjian's criteria [9]. To evaluate the reliability of the measurements, 25 radiographs were randomly selected for re-evaluation by the same observer, and another 25 were evaluated by another observer to assess inter-observer agreement. The intra- and interobserver agreements were evaluated by calculating Cohen's weighted kappa coefficient.

The relationship between the development stage of the teeth and age was analysed, by multiple linear regression, with the development stage of each tooth used as the independent variable. Statistical analyses were performed separately for males and females. The analysis was performed using $\mathrm{R}$ software (ver. 4.0.5; R Foundation for Statistical Computing, Vienna, Austria).

\section{RESULTS}

The weighted kappa coefficients for the intra- and interobserver agreement were 0.9626 and 0.8877 , respectively, indicating very high reliability of the measurements. Table 1 shows the mean and standard deviation age according to developmental stage, as evaluated using Demirjian's criteria, for each tooth. We have not included Stage $H$ in the Table 1 because the upper limit could not be confirmed.

The results of the regression analyses of the male and female subjects are showed in Table 2. The coefficients of determination of the age estimations in this study, derived using only the mandibular posterior teeth, were 0.9634 and 0.9570 for male and female subjects, and the standard errors were 0.75 and 0.81 , respectively. The differences between the chronological and dental ages calculated by the estimation equations in this study are shown in Table 3 and Fig. 1. The mean differences were -0.42 and -0.21 in males

Table 2. Intercepts and coefficients of regression for male and female subjects

\begin{tabular}{|c|c|c|c|c|c|}
\hline \multirow{2}{*}{ Demirjian's score } & \multirow{2}{*}{ Sex } & \multicolumn{4}{|c|}{ Tooth number ${ }^{a}$} \\
\hline & & 34 & 35 & 36 & 37 \\
\hline \multirow[t]{2}{*}{ A } & $M$ & -3.26 & -0.16 & - & 0.19 \\
\hline & $\mathrm{F}$ & -3.66 & 0.32 & - & 0.30 \\
\hline \multirow[t]{2}{*}{ B } & $M$ & -3.08 & 0.08 & - & 0.24 \\
\hline & $\mathrm{F}$ & -3.88 & 0.26 & - & 0.60 \\
\hline \multirow[t]{2}{*}{$\mathrm{C}$} & M & -2.73 & 0.28 & -1.93 & 0.76 \\
\hline & $\mathrm{F}$ & -3.77 & 0.25 & -2.10 & 0.84 \\
\hline \multirow[t]{2}{*}{$\mathrm{D}$} & $M$ & -2.28 & 0.60 & -1.70 & 1.02 \\
\hline & $\mathrm{F}$ & -3.18 & 0.47 & -2.19 & 1.44 \\
\hline \multirow[t]{2}{*}{$\mathrm{E}$} & M & $-1,52$ & 1.24 & -1.15 & 1.89 \\
\hline & $\mathrm{F}$ & -2.81 & 1.23 & -2.03 & 1.71 \\
\hline \multirow[t]{2}{*}{$\mathrm{F}$} & $M$ & $-1,14$ & 1.64 & -1.04 & 2.00 \\
\hline & $\mathrm{F}$ & $-1,69$ & 1.30 & -1.32 & 1.96 \\
\hline \multirow[t]{2}{*}{ G } & $M$ & -0.80 & 2.41 & -0.79 & 3.07 \\
\hline & $\mathrm{F}$ & -1.60 & 1.45 & -1.15 & 3.01 \\
\hline \multirow[t]{2}{*}{$\mathrm{H}$} & M & - & 3.17 & - & 3.84 \\
\hline & $\mathrm{F}$ & - & 1.94 & - & 3.71 \\
\hline \multirow[t]{2}{*}{ Intercept } & $M$ & \multicolumn{4}{|c|}{8.30} \\
\hline & $\mathrm{F}$ & \multicolumn{4}{|c|}{9.43} \\
\hline \multirow[t]{2}{*}{$r^{2 b}$} & $M$ & \multicolumn{4}{|c|}{0.9634} \\
\hline & $\mathrm{F}$ & \multicolumn{4}{|c|}{0.9570} \\
\hline \multirow[t]{2}{*}{ Standard error } & $M$ & \multicolumn{4}{|c|}{0.75} \\
\hline & $\mathrm{F}$ & \multicolumn{4}{|c|}{0.81} \\
\hline
\end{tabular}

M, male; F, female; -, not available.

The dental age can be calculated by adding the intercept to the sum of coefficients corresponding to the tooth developmental stage on the table.

${ }^{a}$ Fédération Dentaire Internationale notation.

${ }^{b}$ Coefficient of determination. 
Table 3. Difference between chronological age and estimated age

\begin{tabular}{lcccccc}
\hline \multicolumn{1}{c}{ Sex } & $\mathrm{n}$ & $\begin{array}{c}\text { Mean difference } \\
(\mathrm{y})\end{array}$ & SD & $\begin{array}{c}\text { Mean absolute } \\
\text { error (y) }\end{array}$ & $\begin{array}{c}\text { Root mean } \\
\text { squared error (y) }\end{array}$ \\
\hline Male & 325 & -0.42 & 0.96 & 0.80 & 0.67 & 1.04 \\
Female & 325 & -0.21 & 0.95 & 0.72 & 0.65 & 0.97 \\
\hline
\end{tabular}

SD, standard deviation.

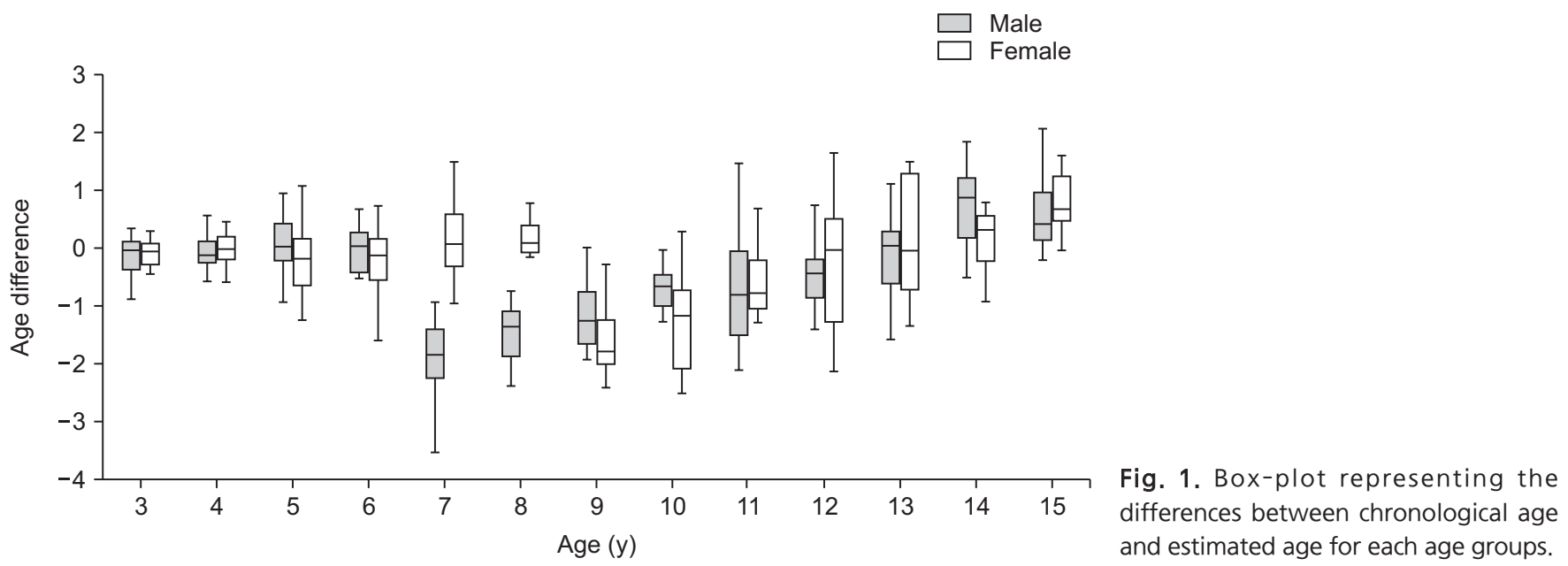

and females, respectively, indicating a slight tendency towards overestimation, and the standard deviations were 0.96 and 0.95 . The mean absolute errors were 0.80 and 0.72 , with root mean square errors of 1.04 and 0.97 , respectively.

\section{DISCUSSION}

In the present study, we derived an age estimation method for use in the Korean population based only on the mandibular posterior teeth. Age estimation should be conducted with consideration of country and ethnicity [14-16]. Age estimation based on tooth development has been reported for the Korean population. In 2008, Lee et al. [10] estimated age according to the degree of development of 28 teeth in children. Dental maturity was evaluated by Demirjian's criteria, and age estimation equations were derived for males and females through multiple linear regression analysis. In 2011, Lee et al. [11] used the dental maturity of seven teeth on the mandibular left side in children. Tooth development stage was determined based on Demirjian's criteria, and the age estimation methods by Demirjian et al. [9] and Willems et al. [12] were tested for applicability to Koreans; a new regression equation was derived through spline regression analysis, and it showed high accuracy.

In 2009, Lee et al. [17] analysed age distribution based on the developmental stage of third molars in Korean adolescents using Demirjian's criteria. In 2010, Lee et al. [18] evaluated the dental maturity of the second and third molars of adolescents using Demirjian's criteria, and reported age estimation methods that assumed that different combinations of molar teeth were available for analysis.

The present study evaluated dental maturity using Demirjian's criteria, similar to other studies that have performed age estimation of Korean children and adolescents. Many studies have suggested evaluating dental maturity for age assessment, including Nolla in 1952 [19], Moorress in 1963 [20], Demirjian in 1973 [9], and Cameriere in 2006 [21]; Demirjian's criteria are widely used [22]. After determining the developmental stage of the teeth, the present study included this as an independent variable in multiple linear regression analysis and derived an age estimation equation for each sex. Various methods, such as simple medianbased, cluster, multivariate, linear regression, multiple regression, and Bayesian analyses are used to evaluate the relationship between tooth development stage and age [23]. The statistical approach of the present study is similar to 
that of Lee et al.'s study [10] and that of Lee et al.'s study [18].

Unlike previous studies, the present study targeted only the four lower posterior teeth; the accuracy was lower than in Lee et al.'s study [10] and Lee et al.s study [11], which also estimated the age of Korean children. The coefficients of regression in Lee et al.s study [10] were 0.9721 and 0.9740 for male and female subjects, respectively, which were higher than those in this study (0.9634 and 0.9570, respectively). Also, in terms of error, Lee et al. [10] reported that, in about 70\% of male and female subjects, the age estimates had an error of 0.5 years or less, while in this study $67.1 \%$ and $71.4 \%$ of males and females, respectively, had errors of 1.0 years or less. Lee et al. [11] reported mean differences between chronological and estimated ages of 0.00 and 0.00 (standard deviations of 0.797 and 0.711 ) in males and females, respectively, whereas in the present study the values were -0.42 and -0.21 (standard deviations of 0.96 and 0.95). The mean absolute errors were 0.481 and 0.621 , respectively, in Lee et al.s study [11], compared to 0.80 and 0.72 in the present study. We attribute these differences to the smaller number of teeth that we used to estimate age; accuracy was improved by using more teeth. This should be considered when applying our method to actual cases.

This pilot study derived a method for estimating age based on the developmental stage of the lower jaw molars in Korean children. In consideration of sex differences, analyses were conducted separately for males and females; we performed regression analysis including the development stage of each tooth as an independent variable, and derived an age estimation equation for each sex. When using only four posterior teeth, the accuracy was lower than when more teeth were used, but the method seems to be useful if the anterior teeth are lost or accurate analysis is difficult due to distortion of panoramic radiographs. Further research using more subjects is needed to verify the applicability of the method.

\section{CONFLICT OF INTEREST}

No potential conflict of interest relevant to this article was reported.

\section{ORCID}

\author{
Byung-Yoon Roh \\ https://orcid.org/0000-0003-1703-3610 \\ Eui-Joo Kim \\ https://orcid.org/0000-0003-0678-8401 \\ In-Soo Seo \\ https://orcid.org/0000-0003-2266-9277 \\ Hyeong-Geon Kim \\ https://orcid.org/0000-0001-5169-4397 \\ Hye-Won Ryu \\ https://orcid.org/0000-0002-9739-3706 \\ Ju-Heon Lee \\ https://orcid.org/0000-0002-4649-4937 \\ Yo-Seob Seo \\ https://orcid.org/0000-0003-1804-5648 \\ Ji-Won Ryu \\ https://orcid.org/0000-0002-5586-8195 \\ Jong-Mo Ahn \\ https://orcid.org/0000-0002-3615-3688
}

\section{REFERENCES}

1. Senn DR, Weems RA. Manual of forensic odontology. Boca Raton: CRC Press. 2013.

2. Thevissen PW, Kvaal SI, Willems G. Ethics in age estimation of unaccompanied minors. J Forensic Odontostomatol 2012;30 Suppl 1:84-102.

3. Franco A, Thevissen P, Fieuws S, Souza PH, Willems G. Applicability of Willems model for dental age estimations in Brazilian children. Forensic Sci Int 2013;231:401.e1-e4.

4. Willems G, Lee SS, Uys A, et al. Age estimation based on Willems method versus new country-specific method in South African black children. Int J Legal Med 2018;132:599-607.

5. Thevissen PW, Fieuws S, Willems G. Human third molars development: comparison of 9 country specific populations. Forensic Sci Int 2010;201:102-105.

6. Roh BY, Lee WJ, Seo JU, Lee UY, Lee SS. Analysis of forensic odontological examinations at the National Forensic Service of Korea from 2011 to 2015. Leg Med (Tokyo) 2018;32:37-42.

7. Lee S, Lim SB, Kim DW, Chung IJ, Kim NY, Lee SS. A Statistical analysis on forensic odontological examination at the NFS from 2007 to 2010. Korean J Leg Med 2011;35:32-41.

8. Kwon CI, Byun JS, Jung JK, Choi JK. An analysis of age estimation cases in Korea from the view of social aspects. J Oral Med Pain 2013;38:235-246.

9. Demirjian A, Goldstein H, Tanner JM. A new system of dental age assessment. Hum Biol 1973;45:211-227. 
10. Lee SE, Lee SH, Lee JY, Park HK, Kim YK. Age estimation of Korean children based on dental maturity. Forensic Sci Int 2008;178:125-131.

11. Lee SS, Kim D, Lee S, et al. Validity of Demirjian's and modified Demirjian's methods in age estimation for Korean juveniles and adolescents. Forensic Sci Int 2011;211:41-46.

12. Willems G, Van Olmen A, Spiessens B, Carels C. Dental age estimation in Belgian children: Demirjian's technique revisited. J Forensic Sci 2001;46:893-895.

13. White SC, Pharoah MJ. Oral radiology: principles and interpretation. Edinburgh: Mosby; 2008.

14. Jeon HM, Kim JH, Heo JY, Ok SM, Jeong SH, Ahn YW. Age estimation by radiological measuring pulp chamber of mandibular first molar in Korean adults. J Oral Med Pain 2015;40:146-154.

15. Lee TH, Hong JH, Lee SS, Kwon JS, Choi JH. Validation of age estimation methods using pulpal volume changes in radiographs for Korean adults. J Oral Med Pain 2014;39:69-77.

16. Lee YH, An JS. Age estimation with panoramic radiomorphometric parameters using generalized linear models. J Oral Med Pain 2021;46:21-32.

17. Lee SH, Lee JY, Park HK, Kim YK. Development of third molars in
Korean juveniles and adolescents. Forensic Sci Int 2009;188:107111.

18. Lee SS, Byun YS, Park MJ, Choi JH, Yoon CL, Shin KJ. The chronology of second and third molar development in Koreans and its application to forensic age estimation. Int J Legal Med 2010;124:659-665.

19. Nolla CM. The development of the permanent teeth. Ann Arbor: University of Michigan; 1952.

20. Moorrees CF, Fanning EA, Hunt EE Jr. Age variation of formation stages for ten permanent teeth. J Dent Res 1963;42:1490-1502.

21. Cameriere R, Ferrante L, Cingolani M. Age estimation in children by measurement of open apices in teeth. Int J Legal Med 2006;120:49-52.

22. Willems G. A review of the most commonly used dental age estimation techniques. J Forensic Odontostomatol 2001;19:9-17.

23. Roberts GJ, McDonald F, Neil M, Lucas VS. The Weighted Average Method 'WAM' for dental age estimation: a simpler method for children at the 10 year threshold: "it is vain to do with more when less will suffice" William of Ockham 1288-1358. J Forensic Leg Med 2014;26:56-60. 